\title{
LA ELITE DE HUAMANGA EN LA INDEPENDENCIA DEL PERÚ 1810 - 1824
}

\author{
THE ELITE OF HUAMANGA IN THE INDEPENDENCE OF PERU 1810 - \\ 1824 \\ (D) Nolberto Claudio Rojas Porras ${ }^{1 *}$, (D) Juan Benigno Gutierrez Martinez ${ }^{1}$ \\ nolberto.rojas@unsch.edu.pe; juan.gutierrez@unsch.edu.pe \\ ${ }^{1}$ Universidad Nacional de San Cristóbal de Huamanga, Ayacucho, Perú
}

*Correspondencia: Nolberto Claudio Rojas Porras. Email: nolberto.rojas@unsch.edu.pe

Recibido: 01.07.21 | Aprobado: 15.07.21

\section{RESUMEN}

La elite de Huamanga constituida por nobles, criollos y mestizos exitosos con base de poder en el comercio, la tenencia y explotación de haciendas, inversiones en la minería, cobro de diezmos, ejercicio profesional y con estilos de vida catalogado "superior", ante el proceso de la independencia actuaron en función a las responsabilidades que tenían con el Estado, su origen social, sus intereses económicos-políticos y la perspectiva del rumbo de los acontecimientos, desde luego asumieron posiciones diferentes. Unos defendieron a la monarquía debido a que sus privilegios e intereses dependía de su continuidad. Otros lo defendieron la Constitución de Cádiz de 1812, las medidas liberales permitieron el acceso al poder a los miembros emergentes y se mostraron partidarios a la independencia como estrategia para cautelar sus bienes y ganar mayores espacios de poder. No faltaron aquellos con posición ambivalente que apoyaron a los realistas e independentistas a la vez. Palabras clave: Huamanga, elite, posición, independencia.

\begin{abstract}
The elite of Huamanga made up of successful nobles, creoles and mestizos with a power base in trade, ownership and exploitation of farms, investments in mining, collection of tithes, professional practice and with lifestyles classified as "superior", before the The independence process acted according to the responsibilities they had with the State, their social origin, their economic-political interests and the perspective of the course of events, of course they assumed different positions. Some defended the monarchy on the grounds that their privileges and interests depended on its continuity. Others defended the Constitution of Cádiz of 1812; the liberal measures allowed the access to power to the emerging members, and they were in favor of independence as a strategy to protect their assets and gain greater spaces of power. There was no shortage of those with an ambivalent position who supported the royalists and the independentists at the same time.
\end{abstract}

Keywords: Huamanga, elite, position, independence. 


\section{INTRODUCCIÓN}

La independencia del Perú es uno de los temas de la historia que ha merecido mayor interés de los académicos, en consecuencia, abundan publicaciones como libros, artículos, reseñas, ensayos desde los primeros años de la era republicana hasta la actualidad, lo cual no implica que el tema se halla esclarecido de todo, más bien han generado nuevas interrogantes que constituyen agenda de investigación y requieren ser repensadas desde nuevas fuentes y teorías. Y precisamente la celebración del bicentenario de la Independencia de Perú, resulta una ocasión pertinente para visibilizar los tramos olvidados y repensar sobre temáticas como el papel de la elite en el proceso separatista.

La región de Huamanga fue un escenario importante de la lucha por la independencia, desde las postrimerías del siglo XVIII hasta 1824, ocurrieron acciones de protesta e insurgencia contra las autoridades y el régimen colonial que ha culminado con la batalla de Ayacucho. Al respecto ofrecen información importante Luis A. Eguiguren en "la Sedición en Huamanga: Ayacucho y la Independencia" historiza la campaña nocturna de colocación de pasquines contra los agentes de la monarquía durante las celebraciones de Corpus Christi en 1812; Manuel Jesús Pozo en "Lo que hizo Huamanga por la Independencia" da cuenta de la rebelión de 1814, Ruiz Fowler en "Monografía Histórica de Ayacucho" y Lorenzo Huertas en "Las luchas por la Independencia en Ayacucho" presentan un resumen completo del proceso separatista en el espacio regional huamanguino; y Virgilio Galdo en "Ayacucho, conflictos y pobreza, siglos XVI - XIX", destaca el papel de los sectores populares en las acciones de lucha contra los defensores del régimen colonial.

Entre los estudios recientes destacan "Historia y cultura de Ayacucho" de Antonio Zapata, Nelson Pereyra y Rolando Rojas, "Huamanga, Historia Tradición y Cultura” de José María Vásquez en las que hacen un balance de la historiografía regional sobre la Independencia; José Luis Igue Tamaki en "Bandolerismo, patriotismo y etnicidad poscolonial: los 'morochucos' de Cangallo, Ayacucho en las guerras de independencia, 1814-1824" analiza el papel de aquel grupo étnico durante el periodo de la independencia; David Quichua "La independencia en la región Huamanga y la Universidad de San Cristóbal 1795-1824" explica la causa del separatismo a partir de la implementación de las Reformas borbónicas. La mayoría de los citados autores han centrado su atención en la génesis, el proceso y el desenlace de la lucha por la independencia, han estudiado el aspecto militar y político, principalmente, en tanto el papel de la elite local fue tangencialmente abordado, poco se sabe de sus integrantes y la posición que adoptaron al respecto.

Respecto a la posición de la elite en la independencia, Scarlett O`Phelan (2011) para la capital del virreinato explica a partir de la distinción de la elite nobiliaria y la elite ilustrada, ambos de composición criolla, pero tuvieron una postura distinta frente al proceso. La elite nobiliaria constituida por aristócratas, en un primer momento apostaron por la independencia, a la que veían como una posibilidad de mantener vigentes sus bases de poder y estilo de vida en un eventual establecimiento de gobierno de una monarquía constitucional; mientras la elite ilustrada conformada por abogados, médicos, clérigos, militares, algunos de los cuáles procedían del interior del virreinato, optaron por un sistema de gobierno alternativo, distinto a la monarquía, la república. 
La explicación de la referida autora permite tener una visión del tema, pero no es generalizable para el conjunto del virreinato, la diversidad existente en la composición e intereses que tenían las elites regionales, definen la singularidad de esta. Según Elizabeth Hernández (2008) el papel de la elite piurana en la independencia se dio en respuesta a dos coyunturas: Primero, durante la crisis hispana y las Cortes de Cádiz, adquirió un protagonismo político asignándose el control absoluto del Cabildo como el medio y espacio de perpetuación del poder regional, desde donde defendieron el gobierno monárquico y profesaron su fidelidad a Fernando VII, dominaron las elecciones para diputados a Cortes, de ese modo continuaron con el ejercicio de poder tradicional dentro de la «política moderna»; pero sus discrepancias e intereses políticos y económicos generó división, unos, defendían los intereses de la elite tradicional y, los otros, los recién llegados, buscaban posicionarse de un espacio de participación política efectiva, se atrevieron incluso a utilizar a la plebe para presionar al primero ceder una parte de su poder. Segundo, durante el desenlace de la Independencia, ante la amenaza de una revolución social de la plebe, el avance de las fuerzas libertarias y la proclamación de la independencia en Piura, se adhirieron interesadamente a la causa separatista, esto para salvaguardar sus intereses regionales, antes que la defensa del nuevo orden, pues las relaciones de parentesco e intereses económicos con los españoles, los vinculaba con el poder español y defendían de manera soterrada a la Corona (Moran, 2010)

Las preguntas para la elite de Huamanga son ¿Cuál fue el rol de la elite en el proceso de la independencia? ¿Qué motivaciones tuvieron tras la posición que asumieron? El desarrollo de las acciones por la independencia desde 1810 hasta 1824 han comprometido de una y otra manera a los miembros de la elite, pues el ejercicio de autoridad, el tener recursos económicos y ejercer poder sobre la población indígena y mestiza, los exponía al accionar de los insurgentes y separatistas que desafiaron el orden instituido por el colonialismo; pero también el proyecto separatista los exponía al futuro, sus expectativas e intereses hizo que asumieran posiciones en función al desarrollo de los acontecimientos y desenlace final. La investigación gira en función a las preguntas e ideas expuestas, para tal se ha recurrido a la información documental del Archivo Regional de Ayacucho y bibliografía pertinente al tema, las que fueron procesadas de acuerdo con las pautas del método histórico.

\section{BOSQUEJO DEL PROCESO DE LA INDEPENDENCIA EN HUAMANGA}

Desde las postrimerías del siglo XVIII, Huamanga fue escenario de acciones de protesta popular contra las autoridades y el régimen colonial, que manifestaron a través de los pasquines anónimos colocados en lugares públicos y puerta del domicilio de familias notables de la ciudad en 1795, el levantamiento de los hermanos José y Rudecindo Castañeda en la doctrina de Pacapausa en 1805, contra el cobro de las alcabalas (Quichua, 2017) Ese mismo año en el pueblo de Tiquihua (Cangallo) estalló una manifestación de descontento protagonizada por los indígenas en contra del párroco de Huayllay, por el despojo de tierras, los elevados tributos, el reparto de mulas y aguardiente y el no pago de salarios (Galdo, 1992; Huertas, 1972; Sala, 1993)

En 1809 ocurre una manifestación antirrealista de artesanos, comerciantes y campesinos en Huamanga, hecho que tenía cierta vinculación con el movimiento antifiscal 
ocurrido en La Paz (Bolivia). En 1811 en Huanta apareció un grupo autodenominado "Alzados de la Paz", que tenía planes de levantarse y combatir contra los españoles. En Huamanga circulaba información que la noche de 28 a 29 de junio de 1811 estuvo destinada para el exterminio de los españoles y de algunos patricios realistas; pero el fracaso de Castelli en la batalla de Huaqui acobardó y soterró por entonces aquel plan. (Eguiguren, 1935)

Las elecciones de Cortes aumentaron los entusiasmos de un lado y los recelos del otro; los rebeldes aprovecharon el momento, lanzaron pasquines y tornaron sediciosos a sus amenazas contra las autoridades (Eguiguren, 1935) A mediados del mes de abril de 1812, por revelación de un infidente, el gobierno de Huamanga recibía aviso de un plan de rebelión programada para la novena de Corpus Christi, que tenía por objetivo ejecutar a los españoles. La delación de aquel plan, mataron en el cascaron una insurrección prevista en la ciudad (Husson,1992), pero no pudo evitar la colocación de los pasquines anónimos en los lugares públicos de la ciudad durante las noches del mes de mayo, en las que insultaba y amenazaba de muerte a las autoridades, españoles y algunos criollos identificados con los realistas, y concitaba al vecindario para un levantamiento general. A falta de gacetas en que se dieran a conocer las ideas de la libertad y otros derechos del ciudadano, los pasquines calaron en el ánimo del pueblo (Eguiguren, 1935).

En 1813 los indios de las alturas (punas) de Huanta se sublevaron contra las autoridades coloniales (Husson, 1992), Huamanga entró a una conspiración sorda (Medina, 1924) En 1814 el temor y la inestabilidad volvió por el estallido de la rebelión de los hermanos Angulo y del curaca Mateo Pumacahua en Cusco. La facción al mando de Hurtado de Mendoza, José Gabriel Béjar y Mariano Angulo, se dirigieron a Huamanga, ante su proximidad el 31 de agosto, estalló una revuelta popular en la que madres, mujeres y hermanas de los milicianos "levantaron el grito contra la partida de sus maridos y relacionados, se metieron en los cuarteles y los indujeron a salir con las armas en la mano para emplearlas en romper las puertas de algunas tiendas de comercio, que saquearon con otras casas de particulares" (Sala, 1989, pp 657)

En los siguientes días, ante la noticia del inminente arribo de los insurgentes del Cusco, el Intendente Paula Pruna y "muchos vecinos emigraron, ocultando sus alhajas y valores porque presagiaban el saqueo y el desastre" (Ruiz, 1924, pp 96) El día 20 de setiembre de 1814, llegaron a la ciudad acompañado por los morochucos de Pampacangallo y su líder Basilio Auqui, y nuevamente se cometieron excesos. El Cap. José Vicente de la Moya que se hallaba oculto en el Convento de San Francisco de Asís, fue sacado por la multitud y luego dieron muerte. En los siguientes días permanecieron en la ciudad, dispusieron de los bienes inmuebles de algunos vecinos, como la casa del Marqués de Mozobamba y del Pozo, ubicada en plena Plaza Mayor de la ciudad, fue convertida en su cuartel (ARAy, Protocolo notarial, Leg. 168, 1814-1816), muchos mestizos e indios de la ciudad, de los pueblos aledaños se enrolaron a sus filas y con quienes se dirigieron a Huanta a luchar contra las fuerzas españolas que allí se encontraban al mando del Crnel Vicente Gonzales. Los enfrentamientos se produjeron los días 1 y 2 de octubre, culminó con el triunfo realista, quienes luego se dirigieron a Huamanga a recuperar la ciudad y perseguir a los insurgentes que se prolongó hasta el 4 de febrero de 1815, fecha en que derrotó a los cusqueños en la localidad de Matará (Rojas, 2016). 
En esta rebelión muchos hacendados y comerciantes resultaron seriamente afectados, pues las tropas en contienda dispusieron de ganados y productos para cubrir las necesidades del momento, así también de las mercancías como tejidos y otros enseres. En tanto los morochucos, a pesar de la derrota de Hurtado de Mendoza, continuaron con los sabotajes y lucha contra las huestes españolas, saquearon haciendas y casas, asaltaron a viajeros, amenazaron a los realistas y sus aliados hasta el año de 1824 (Igue, 2008).

En 1818 las campanas de las iglesias fueron echadas al vuelo subrepticiamente alarmando a la población; y la propaganda revolucionaria, por medio de los pasquines se torno más profusa y cáustica. En ese año Huamanga comienza a despoblarse, algunos españoles vieron la acción irreversible de insurrección huamanguina y otros pueblos, se embarcaban hacia España mientras otros permanecían en la ciudad con la esperanza del triunfo realista. De enero a octubre de 1820 se produce constantes manifestaciones anticoloniales, ante el arribo del Gral Antonio Álvarez, la autoridad local y la población lo recibieron efusivamente (Huertas, 1974).

La autoridad realista en su propósito de restablecer la autoridad y el orden designó para tal al general Mariano Ricafort y luego a José Domingo Carratalá, quienes se han caracterizado por emprender campañas de saqueo y exterminio a la población cangallina (Huertas 1974, Ruiz, 1924) y mandaron ejecutar públicamente a María Parado de Bellido y Basilio Auqui. La población ha persistido en la lucha hasta ver culminada el triunfo patriota en la pampa de Ayacucho.

\section{LA ELITE DE HUAMANGA}

Los Marqueses de Feria y los de Mosobamba... los Tello de Espinosa, Marqueses de Valdelirios, parientes del almagrista Juan Tello de Guzmán y descendientes del Encomendero de Chinchaycocha, Juan Tello de Sotomayor, el que prendió a Hernández Girón ... los La Fuente, Marqueses de San Miguel de Hijar... una rama de los Carrillos de Albornoz de Montemar; los Oblitas, los Maysondos, los Romanís, los Orés; y durante largos periodos de mando, como Corregidores o Intendentes, los Bozas y Solís, de los Marqueses de Casa-Boza; los Vásquez de Acuña, de los Condes de La Vega del Ren; el Vizconde de Miraflores; y los Manriques de Lara, Marqueses de Lara, y Señores de Amusgo y Redecilla en España, de la alcurnia y tronco de los antiguos Duque de Nájera, como procedentes de Don Rodrigo Manrique... (De la Riva Agüero, 1995, pp 127)

Las referidas familias residían en la ciudad de Huamanga hacia mediados del siglo XVIII, según Juan y Ulloa, hallaron en ella "cerca de veinte familias nobles, que ocupaban el centro de la ciudad y cuyas casas son por lo regular altas, construidas de piedra, bien labradas y cubiertas de teja" (De la Riva Agüero, 1995, pp 127) de ahí que el citado autor lo cataloga como una "sociedad aristocrática". Aquellas familias formaban parte de la elite local, por su condición noble gozaban de privilegios y tenían una posición dominante en la sociedad. La creciente decadencia económica y las rebeliones indígenas ocurridas durante la segunda mitad del siglo XVIII hicieron que parte de ellas pasaron a residir a Lima (Vásquez, 2015). Para los primeros años de la centuria siguiente quedaban como vecinos de la ciudad, la familia de los marquesados Mozobamba, de Feria, Valdelirios, Bosa y Lara. 
También residían en la ciudad connotadas familias y personalidades como los hacendados Ruiz de Ochoa, Monrreal, Cabrera, Palomino, Flores, Marcelo Castro, Francisco García; los comerciantes Mariano López, Rafael Muñoz, Gregorio Ulloa, Juan Frías, Ignacio Ore, Vicente Ruiz, Nicolás Olano, Mauro Pantoja, Vicente Egurrola, Pedro Zorraquin, Miguel de Yriarte, José Egurrola y otros; los miembros del clero el Obispo de la ciudad, los curas Mariano Chevaguren, Fernando Oller y Casimiro Cervantes; los de cabildo secular Francisco Hernández, Fernando Fernández, Francisco Paula (Rojas, 1995) La mayoría eran de origen criollo y algunos mestizos exitosos.

Este conjunto de familias y personalidades constituían la elite de Huamanga, en el ámbito local eran conocidos como «vecinos notables» con estilos de vida y prácticas culturales catalogado "superiores", con la que se diferenciaba del pueblo "incivilizado y salvaje", ejercían poder sobre los otros, tenían una posición influyente y hegemónica en la sociedad de aquel entonces, gracias a la concentración de los recursos de poder, como el ejercicio de cargos militares, políticos, burocráticos y religiosos de importancia; a su capacidad económica por tenencia y explotación de haciendas, manejo de tiendas comerciales en la ciudad, inversiones en la minería, cobro de diezmos, otorgamiento de préstamos entre otros, justificadas por su ascendencia española y la educación, y legitimadas por las reglas del colonialismo.

Parte de los miembros de la elite ejercían cargos en la administración colonial, de ahí que también es denominado la elite de poder (Mills 1984, Baras 1991 y Blacha 2005). Un miembro del marquesado local ha tenido la trayectoria burocrática siguiente

Don Gaspar Carrillo de Albornoz Vega Munibe, IV Márquez de Feria y V Márquez de Valdelirios Caballero de Carlos II y de San Hermenegildo, alcalde de Lima en 1790 y 1791, gentil hombre de cámara S.M. con entrada, Contador Mayor del Real Tribunal de Cuentas de Lima, desde 1808 hasta 1810; coronel, ascendido a Brigadier en mayo de 1814; presidente de la Real Audiencia de Charcas en 1816. Había ordenado el Rey, en 2 de mayo de 1815, al Virrey Abascal, le confiera la Intendencia de Lima, la Presidencia del Cuzco o la Sub-Inspección de Tropas del Perú. (Vásquez, 2015, pp 30)

El general Nicolás de Bosa y Solís, del marquesado de Casa Bosa, fue corregidor de Huamanga. Los otros miembros, también ocuparon cargos políticos y administrativos en la administración colonial el que se ilustra en el siguiente

\section{Cuadro N. ${ }^{\circ} 1$}

Miembros de la elite que desempeñaron cargos

\begin{tabular}{lllll}
\hline Nombre & origen & Ocupación & año & Cargo \\
\hline José Soto & & comerciante & 1813 & $\begin{array}{l}\text { Diputado del ilustre } \\
\text { ayuntamiento }\end{array}$ \\
& & & 1813 & Juez y diputado de comercio \\
José Vicente Egurrola & peninsular & comerciante. & 1814 & Alcalde de segundo voto \\
& & & 1819 & Regidor
\end{tabular}




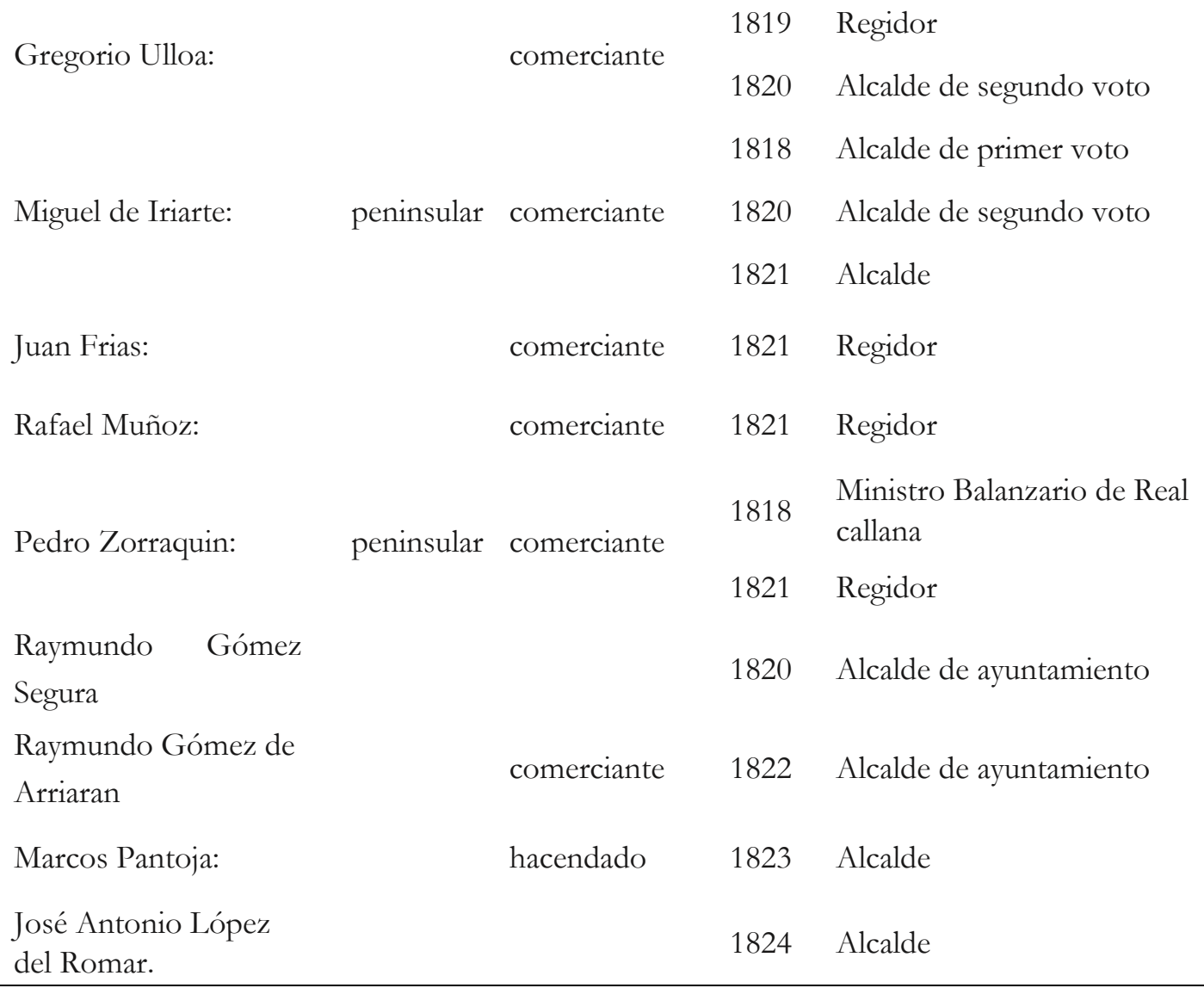

Fuente: Rojas (1995) / Sala, 2011: 11

La mayoría de los integrantes de la elite poseían haciendas, que además de ser la fuente de ingresos económicos, afianzaba el poder y el prestigio social. El Marqués de Valdelirios, tenía por propiedades, las haciendas de Ocuschay, Lloqlla, Huanchuy, Vega, Isqana, Cucho, Tutupa, La Legua (Lima y Callao) los hatos de Chaca, Cusibamba, Chalcachuco, Airampo, Pampamarca y Mosoqcancha, además casas y pulperías en la ciudad de Huamanga y al morir dejó en su "testamento catorce millones de pesos" (Pozo, 1924, pp 7). Don Nicolas de Bosa y Solis declaró por sus bienes

La hacienda cañaveral de Socos tasada en 84,000 ps, el hato de Ranracancha, hacienda de Chacabamba en 96,000 ps, la hacienda Rayan que tenia 800 vacas, 160 buyes, 62 reses, 6 pearas de mulas, 52 burros, asi mismo 1,200 fanegas de maíz, 100 fanegas de trigo y otros bienes que avalúan en 40,000 ps. La hacienda de Chumbibamba en Talavera -declaro ser arrendatario del obraje de Pomacocha, diezmero de Ongoy... declaro que siendo el cumulo de mis bienes según las relaciones que tengo hechos en ellos 418000 ps deben extraer de ello 48000 ps que importaran mis deudas declaradas y 10000 ps de comunicado y quedan líquidos de capital 360000 ps declaro por mis bienes en poder de Francisco Bosa en Oruro los 4500 arrobas de azúcar de los que importa los 27,000 ps declaro que de ultimo resto tengo que entregar al obraje de Ccaccamarca 303 arrobas (ARAy. Prot. Not. Leg: 91. 1774)

También contaban con haciendas en la zona de yunga (Huanta) donde cultivaron la coca; en los valles interandinos la caña de azúcar y frutales; en la zona quechua los 
granos, y en la región de puna criaron animales como vacunos, equinos, ovinos y otros, los cuales eran destinados a diferentes mercados.

José Palomino era dueño de la hacienda Canónigo, los alfalfares y tierras de Yanamilla; además, era coronel de las fuerzas realistas... asimismo, el presbítero Tadeo Cordero usufructuaba en la ceja de selva la hacienda cocal La Merced y; Don Martín Armendáriz, además de desenvolverse como coronel de las fuerzas reales, era dueño de la hacienda cocal Paraíso, ubicada en la selva de Huanta, la cual alquilaba al teniente de milicia, Joaquín Ozaeta. (Quichua, 2020, pp 51)

En el registro de tributarios para 1823 figuran parte de los hacendados con propiedades en las cercanías de la ciudad.

\section{Cuadro $\mathbf{N}^{\circ} 2$}

Hacendados con propiedades cercanas a la ciudad

\begin{tabular}{lll}
\hline Nombre del hacendado & Hacienda/fundo & Valor \\
\hline Mariano Tueros & Molino Loreto y tierras accesorios & 6,600 \\
Cnel. José Palomino & Molino Canónigo, alfalfares y tierras de & 10,000 \\
Sras. Infanzón & Sta Elena & 6,000 \\
Vicente Ruiz & Chaca & 10,000 \\
Pedro Caminada & Cabrapata & 3,000 \\
Justo Flores & Chocan y huerta Ayamanchi & 3,000 \\
Márquez de Feria & Tierras de Pampa de Arco & 2,600 \\
Josefa de la Riva Cosío & Chupas & 7,000 \\
Pedro José Palomino & La Totora, Las Totorillas y otras tierras & 16,000 \\
Cnel. José Palomino & Tartaria & 2,000 \\
María Josefa Palomino & Tartaria & 2,500 \\
Jacinto Infanzón & Caballitos & 3,000 \\
Gregorio Flores & Motoy y Hato Ataguisuar & 7,000 \\
\hline
\end{tabular}

Fuente: ARAy. Intendencia, leg: 40. 1823 elaboración propia.

El comercio fue la otra ocupación para muchos miembros de la elite local, según Urrutia "el comercio huamanguino a gran escala estuvo hasta la Independencia en manos de comerciantes españoles, principalmente de origen vasco como Irribaren, Longaray, Garayoa, Pertica, Soregui, Murrieta, Egurrola, Zorraquin, Lartegui, a ellos se suman los comerciantes que adquirieron capital a partir de su origen terrateniente aristocrático Ignacio Ore, Nicolas Olano y Jauregui” (1983: 27). Así también Mauro Pantoja, Raymundo Gómez, Santiago Castro, Simón Tueros, Gregorio Ulloa, Juan Frías, José Soto y Rafael Muñoz (Rojas, 1995)

Comercializaban efectos de Europa, textiles, coca, aguardiente y otros enseres. Raymundo Gómez y Vicente Egurrola en sus tiendas, ofrecían telas finas importadas de 
Europa: pañoletas de seda, varas de algodón, pañuelos estampados de colores, manguillas blancas de gaza, polares de pecho, medias de gaza blanca y varas de casimir negro, productos bienquistos por el pujante y creciente grupo de poder huamanguino (Quichua, 2020). Mauro Pantoja señaló que "manejó una tienda de comercio de efectos de castilla en que habrá 15 a 16 mil pesos" (ARAy, Prot. Not, Leg: 178, 1813). Ignacio Ore hizo mención

Declaro por mis bienes 16,000 ps en efectos de comercio así de castilla como de la tierra, plata sellada y demás que existen dentro y fuera de la mercancía como en fanegas de trigo, añiles, bayetones, tocuyos y demás cosas” (ARAy, prot. Not. 178.

El aguardiente era la otra mercancía que comercializaban en grandes volúmenes, Fermín Lino Enríquez, vecino y hacendado en el valle de Palpa en el compromiso celebrado señala que del capitán don Vicente de la Moya he recibido los 1800 ps para entregar en el pueblo de Tambo (Guanta) 40 botijas de aguardiente de buen paladar, 240 arrobas en odres en el mes de mayo en Tambo y en esta ciudad 60 botijas de a 5 arrobas a fines de agosto que estas partidas hacen a 600 arrobas de aguardiente (ARAy, Prot. Not, Leg: 16, 1811)

El comercio permitía adquirir riquezas y ampliar la inversión en otros rubros, como la minería, cobro de diezmo, préstamo de dinero y adquisición de bienes inmuebles: casas y haciendas, de ahí que era común para muchas familias desarrollar varias actividades a la vez. La declaración de Mauro Pantoja acredita parte de lo señalado

Declaro al casarme no tuve bienes de que hacer capital tampoco recibí dote alguno.... Declaro por mis bienes adquiridos una hacienda la Deseada, - haber comprado dos casas el uno en 2000 ps y el otro en 1500 ps, -haber comprado por tres vidas del Monasterio de Santa Teresa la hacienda nombrada Ccaccamarca en Ocros, -haber adquirido una tienda de comercio de géneros de castilla surtida cuyo importe no puedo calcular - debo al comerciante Roman Boloña la cantidad 700 ps procedentes de géneros de castilla (ARAy. prot. not. leg: 157. 1843)

\section{EL PAPEL DE LA ELITE DURANTE LA INDEPENDENCIA}

Las luchas por la independencia en Huamanga han involucrado en su desarrollo a los diferentes sectores de la sociedad, los miembros de la elite no quedaron ajeno a ella, el poder político y económico que ostentaban los expuso a los hechos de la coyuntura, pues unos han tenido que actuar en cumplimiento de las responsabilidades que les competía por el ejercicio de cargos como autoridades, funcionarios, militares y religiosos; otros padecieron los efectos de las acciones que se produjeron. Lo señalado es insuficiente para explicar la posición y papel que asumieron respecto al proceso separatista, pues también intervinieron otros factores como el origen social, los intereses personales y la coyuntura política.

En los antecedentes se cuenta las reformas borbónicas, según Quichua (2019) la implementación de aquellas reformas trastocó los privilegios tributarios, la autonomía de los fueros y las prácticas corruptas en los sectores sociales más preponderantes, es decir en la elite, de ahí que unos pretendían restaurar las prerrogativas afectadas, otros aspiraban 
la separación encabezados por el doctor Francisco Pruna Aguilar. Así también se tiene la influencia de nuevos pensamientos económicos, según Huertas (1974) los grandes comerciantes impregnados de las ideas burguesas que llegaban vía Buenos Aires-Cusco, entraron en pugna con los señores hacendados feudales y con la Corona, lo expuesto deja manifiesto la existencia de posiciones e intereses frente a un proceso separatista que comenzaba a emerger.

Durante la crisis de la monarquía española, en la sucesión en el trono de Fernando VII por la abdicación de su padre Carlos IV "Huamanga se había adelantado a la capital pues en ella se hizo la proclamación de Fernando el día 2 de octubre - 1808 - seguiole el Cusco luego Arequipa... estos sentimientos de general adhesión a la persona del Rey demuestran que en el Perú, no había cundido las ideas separatistas, aunque no faltaban partidarios de la independencia" (Vargas, 1971, pp 193) La proclama fue principalmente iniciativa de las autoridades de la Intendencia y el cabildo en la que participaron los vecinos de la ciudad. En los años siguientes con la formación de las Juntas de gobierno y la puesta en vigencia de la Constitución de Cádiz de 1812, la posición de la elite se hizo más diversa, así solo entre los partidarios del realismo, según Sala (2012) había realistas absolutistas, liberales o incluso quienes se identificaron con ambas tendencias. Los absolutistas defendieron a los reyes; en tanto los liberales aprobaron y pusieron en marcha la Constitución de 1812, defendieron la autonomía local manteniéndose en sus cargos hasta 1824, incluso después.

La defensa de la monarquía asumió principalmente, las familias nobles, las autoridades políticas y militares (Intendente, mandos militares), hacendados, mineros que poseían riquezas y gozaban de privilegios al amparo de la autoridad real, la insurgencia era un peligro para su situación. En los pasquines anónimos colocados durante la sedición de 1812, se pone de manifiesto a quienes defendían a la monarquía despedirse del mundo: llegará el feliz día en que se verán abatidos todos los advenedizos y los Palominos, y reinarán los criollos, gobernaran los patricios, perecerán los traidores que son sujetos como: Pruna, Harrea; Cosio; Noboa; al señor Dean se venera y se desea bien; los dos Roizes; los Olanos; Los Calines y a los otros se pasa; Toledo, Coronel Palomino y su hermano y los hijos, Moya, Cantón, Santillana, sujetos que merecen ser quemados sobre vivos; Camino, Muxica y el joven Olanito están ya seguros en Guanta allá dispondrán, pagarán bien pagado como lo merecen, mejor está Moya en el Cuartel para hacer montar a un cañón, ese Sargento Tobedo, con el zambo Vizcarra, desollados y cortadas las lenguas, como si fuera gente el zambo Coronel Palomino, vá Tobedo a avisar señor en tal parte hay juntas, como si fuera gente, pero vive Dios pocos días faltan; pidan auxilio a Cangallo, a Guanta y verán: tengan por bufonada si el famoso coronel no deja el mando será perseguido por que ni gusta el batallón, en fin veremos, no es uno solo sino quinientos; no parece este señor Capitán ya camino un propio, y veremos (Eguiguren 1935, pp 54)

La mayoría de las personas referidas en el pasquín ocupaban cargos públicos en la administración colonial, así Francisco Paula Pruna (encargado de la Intendencia) José Muxica (protector de naturales, promotor fiscal de Real Hacienda), Antonio Ruiz (regidor y teniente coronel), Francisco Ruiz (coronel y gobernador interino), Nicolas Olano (teniente coronel), José Lucas Palomino y José Palomino tenían el grado de coronel, 
Vicente de la Moya (capitán), Domingo de Cosío (marqués de Mozobamba) y los otros eran parte del cuerpo militar en la ciudad.

Durante la rebelión de 1814, el hacendado José María Palomino, regidor del ayuntamiento constitucional de la ciudad hizo referencia notorio es que en la insurrección de 1814 mi hacienda de vacas nombrada Sachabamba en Cangallo fue el centro de correrías de los insurgentes y morochucos [...] quienes por castigar mi inequívoca fidelidad al rey nuestro señor se robaron casi todo el ganado vacuno y caballar [...] de manera que de centenares de vacas y caballada que en ella tenía apenas recogí después cincuenta y tantas cabezas de ambas especies y la casa todas incendiadas. (ARAy. Intendencia. 42, Año: 1820 folio 77)

Nicolás de Olano, teniente coronel de milicias y regidor de ayuntamiento constitucional señaló que "consta que en la revolución de 1814 tuve tres cosas: la gloria de cooperar en la victoria de Huanta, el triste honor de recibir un balazo y la desgracia de ver quemada mi hacienda" (ARAy. Intendencia. Leg: 42. 1820). Similar historia declaró el peninsular Vicente Ruiz Adan.

[...] yo he experimentado siempre los furores de los movimientos políticos ya que no he tenido la desgracia de sufrir en persona, los he pagado con mis bienes por el año de 1814, me arruinaron la hacienda y la casa en tal manera cuando volví de mi emigración tuve que alojarme en casa ajena [...] (ARAy, Intendencia. Leg: 42, 1820)

En los años siguientes aquella facción se redujo a las personas que tenían mayor grado de vinculación con la administración monárquica, entre las figuraron altos mandos de la tropa realista, funcionarios de la Intendencia, el obispo y algunos peninsulares, hicieron esfuerzos por mantener y garantizar el orden colonial, con ese propósito el 19 de febrero de 1820, ante el avance de la expedición libertadora del General San Martin, se congregaron en la sala capitular de la ciudad, el coronel Gabriel Herboso jefe político de la provincia y los señores Joaquín de Olivares Teniente Coronel de Regimiento Imperial Alexandro, Dr. Luis de Aristibal prebendado de la Santa Iglesia, don Miguel de Iriarte Alcalde de Primera Nominación y Juez Diputado de Comercio, don Pedro Zorraquin con Bernardo Saez regidor y síndico procurador de ayuntamiento constitucional y don José del Pozo Ministro contador de las cajas reales, para apoyar a las fuerzas realistas bajo la justificación siguiente “... exitando el patriotismo de esta junta y zelo por la causa justa para suplir la falta de numerario se acordó formar una lista de préstamos de vecinos pudientes y de donativos para el restablecimiento del sistema político..." (ARAy. Intendencia. Leg: 42, 1820)

Cuadro $\mathrm{N}^{\circ} .3$

Resumen de los prestamos fijados y obtenidos

\begin{tabular}{llll}
\hline Grupo & $\begin{array}{l}\text { Cantidad de } \\
\text { personas }\end{array}$ & Monto solicitado & $\begin{array}{l}\text { Monto } \\
\text { prestado }\end{array}$ \\
\hline Comerciantes & 14 & 22,000 & 11,900 \\
Hacendados & 16 & 12,600 & 3,900 \\
Clero & 17 & 20,000 & 3,700 \\
\hline
\end{tabular}




\begin{tabular}{lccc}
\hline Cabildo secular & 3 & 5,500 & 4,200 \\
Señoras pudientes & 7 & 6,000 & 1,800 \\
Curas y hacendados de & 9 & 11,500 & \\
Andahuaylas & & 77,600 & 25,500 \\
TOTAL & 68 & & \\
\hline
\end{tabular}

Fuente: Rojas (1995: 51-53). Elaboración propia.

De las 68 personas solicitadas la mayoría alegaron su imposibilidad de cumplir por las pérdidas que tuvieron en 1814 y aportes hechos anteriormente. El incumplimiento si bien respondía a las razones señaladas; pero también al parecer era una estrategia de acomodamiento al nuevo escenario que se perfilaba con el triunfo de las fuerzas independentistas. En los años decisivos de la independencia pocos mantuvieron su lealtad a la corona, lo que les costó el embargo de sus bienes decretado por el Juzgado Privativo de Secuestros de Ayacucho en 1825.

Son comprendidos todos los que huyeron con los enemigos aun cuando hayan vuelto al seno de sus familias por no favorecerles la capitulación de Ayacucho, con respecto a los bienes que existía en el territorio ocupado por el gobierno independiente al tiempo que aquella se concedió” (ADAy / Juzgado de 1ra Instancia/ leg: 01, 1825)

Del total de 27 personas comprendidas figuraban los siguientes miembros de la elite: el marques Gaspar Carrillo de Albornoz, Vicente Egurrola, Miguel Iriarte, Raymundo Gómez Segura, Fernando Fernández, Raymundo Gómez Arriaran, Brianda Cabrera, Pedro Zorraquin, Nicolás Olano, Mariano Chevaguren, Vicente Ruiz, Cayetano del Hierro, Marcelo Castro, miembros de la elite (ARAy, Juzgado de Primera Instancia. Leg: 01. 1825)

La facción de la elite con postura de realismo liberal emergió con la puesta en vigencia de la Constitución Liberal de 1812, las reformas políticas como la supresión de regidurías perpetuas, la elección para los cargos en el cabildo, en adelante denominados como ayuntamientos, han permitido el acceso al poder de personas que se hallaban al margen del tradicional círculo de poder. En la primera etapa del liberalismo (1812-1814) para el cargo de alcalde de la ciudad, en la elección de 1813 resultó electo el comerciante Gregorio Ulloa y en 1814 Francisco de Araujo (Sala, 2012). Por otra parte, la administración de justicia también fue reformada, los jueces fueron limitados a intervenir solo en asuntos contenciosos de su partido, ello ha ocasionado mayor requerimiento de jueces que fue copado por abogados locales, asimismo en los otros cargos públicos como -auditores de guerra, asesores de ayuntamientos, secretarios de diputaciones provinciales...- y la mayoría de las representaciones electivas -diputados a Cortes y Diputaciones Provinciales, más alcaldías y regidurías municipales (Sala, 2016).

Algunos criollos llegaron a ser elegidos para el cargo de diputado por Huamanga ante las Cortes de Cádiz, Miguel Ruiz de la Vega para las ordinarias de 1810 y luego Martín José de Mujica y Pedro José Tello (titulares) y Pedro Lazon y Garma (suplente) para la de 1813 y 1814 (Paniagua, 2003). Así también los dos últimos intendentes fueron criollos “Manuel Quimper (1816-1819) y Francisco José de Recavarren, chileno, que fue sucedido 
interinamente por su yerno, Gabriel Herboso, cuando murió de una severa disentería en 1820" (Fisher, 2006, pp 160).

Con las reformas constitucionales los criollos que se hallaban al margen del poder tuvieron oportunidades para acceder a cargos públicos y exigieron el cumplimiento de las medidas propuestas, cuando se les cerró el paso legal a sus aspiraciones se insurreccionaron, a este grupo se sumaron los miembros que se mostraban contrarios a las medidas implantadas por las reformas borbónicas. El Intendente de Huamanga en su informe al Virrey señalaba que "entre los patricios había un fermento de insurrección no despreciable, lo cual era creíble porque había rivalidad entre patricios-criollos que por su riqueza descollaban en la ciudad - y españoles era visible” (Eguiguren, 1935, pp 26).

Las nuevas autoridades del ayuntamiento/cabildo hicieron de aquello en el espacio de aprendizaje del liberalismo, no huyeron ante el arribo de fuerzas insurgentes y separatistas, salieron al encuentro, organizaron actos de recepción. En la rebelión de los hermanos Angulo de 1814 según Roel "en su campaña llegaron a contar con la adhesión de los cabildos de Abancay, Andahuaylas, Huamanga, Huancavelica, Puno y la Paz” (1988, pp. 154). En 1820 durante el paso por Huamanga del Gral Antonio Álvarez de Arenales, según el coronel José Segundo Roca lo recibieron.

El 31 de octubre de 1820, hicimos nuestra entrada en la ciudad de Huamanga ... la Municipalidad, los vecinos notables de la ciudad, y algunos miles de habitantes de todas las clases de la sociedad, salieron a recibirnos a distancia de mas de 19 o 20 cuadras de los suburbios... asi que anduvimos algunas cuadras, encontramos a los señores de la Municipalidad con sus altas varas negras... se acercaron al general dirigiéndole un discurso el principal de ellos, y haciéndolo la demostración de ofrecerle la llave de la ciudad... (Roca, 1866, pp 29). (cursiva mía)

No solo recibieron sino también junto a muchos vecinos notables y la población participaron de la declaración de la independencia (Roca, 1866); pero a su retiro se pusieron al servicio de la tropa realista, según Quiroz "allí donde las fuerzas realistas tuvieron el dominio, las elites criollas permanecieron leales al rey. En cambio, allí donde el régimen colonial no pudo mantenerse, la opción fue por la separación. Estas alternativas fueron variando tanto en el tiempo como en el espacio y las indefiniciones de esta guerra larga, necesariamente afectaron a todos sus protagonistas" (2009, pp 226)

Con el retorno a los dictados constitucionales gaditanos en 1820 que se prolongó hasta mediados de 1824, se volvieron a implantar los principios liberales de la Constitución de 1812, la coyuntura dominada por la guerra además se caracterizó por cambios profundos en la concepción del poder basado en la división de poderes, la abolición del complejo entramado político del absolutismo, y la introducción de un modelo de gobierno representativo en lo local y provincial, que daría cuotas significativas de autogobierno y autonomía a los habitantes de Arequipa, Cusco y Huamanga (Sala, 2011) 


\section{Cuadro $\mathrm{N}^{\circ} 4$.}

Alcaldes de Huamanga durante el trienio liberal

\begin{tabular}{|c|c|}
\hline Año & Nombre \\
\hline 1820 & Raymundo Gómez de Segura \\
\hline \multirow{2}{*}{1821} & Miguel de Yriarte \\
\hline & José Soto \\
\hline \multirow{2}{*}{1822} & José de Gálvez \\
\hline & Raymundo Gómez de Arriaran \\
\hline \multirow{2}{*}{1823} & José Carrasco \\
\hline & Marcos Pantoja \\
\hline \multirow{2}{*}{1824} & José Antonio López del Romar \\
\hline & José Luis de Ochoa \\
\hline
\end{tabular}

Fuente: Sala 2011: 711

En el mismo periodo los señores Raymundo Gómez de Segura, José Gálvez, Rafael Muñoz, José Carrasco, Gregorio Flores, José López fueron designados para ejercer el cargo de Juez conciliador (Sala, 2012). El acceso a los cargos públicos se dio gracias a las reformas constitucionales. El sistema representativo gaditano había generado un espacio de aprendizaje para los partidarios de la libertad, las personas identificadas y participantes del liberalismo han logrado el transito sin mayores inconvenientes, participaron en la conducción de las instituciones locales y provinciales en la naciente República peruana. (Sala, 2011). A manera de ejemplo José Soto, fue alcalde de ayuntamiento en 1820 y 1821 , también ejerció el mismo cargo en los años de 1825, 1830 y 1832; Francisco García fue alcalde en 1819 y 1831. (Rojas, 1995)

Durante los años de consolidación de la independencia (1821-1824) algunos actuaron de manera ambivalente, estaban a la expectativa ante el nuevo orden republicano que se había impuesto en el Perú y procedieron en perspectiva de sus intereses propios antes que la defensa del colonialismo o la independencia, se resistieron a los requerimientos económicos para solventar la guerra, pero otorgaron empréstitos bajo la expectativa de obtener ganancias por los intereses en un futuro próximo

Pedro Zorraquin [comerciante peninsular] para acreditar no hacer la menor ocultación de los bienes que he tenido [...] refirió que con el Rey tiene perdidos más de 40,000 ps en préstamos y suplementos a la fuerza, iguales empréstitos a la patria que pasan los 8,000 ps fuera de otros muchos quebrantos que ha padecido en la presente compulsiones políticas. (ARAy. Juzgado de Primera Instancia. Causas civiles. Leg: 01, año: 1825)

El comerciante Julián Gonzales, manifestó haber brindado su apoyo a los patriotas

He concurrido voluntariamente al socorro de la patria en las circunstancias de necesidad [...] al arribo del Señor General Arenales por el año pasado de 1820 
contribuí voluntariamente con 1000 ps en dinero para las urgentísimas necesidades de aquella expedición [...] el ejército unido estaba en necesidad de vestuario y por conducto de mi esposa [...] hice donación de 4000 piezas de bayetones efectos de mi giro. (tomado de Solier 1995: 20)

Para aquellas personas la seguridad de sus intereses económicos y políticos estaba por encima de la defensa del régimen político, actuaron en función de quien los garantizaba la conservación de esta y las expectativas de obtener beneficios.

\section{A MODO DE CONCLUSIONES}

1. La Intendencia de Huamanga fue escenario de las luchas por la independencia, con antecedentes que se remonta hasta las postrimerías del siglo XVIII, desde entonces han ocurrido muchas acciones de protesta y rebelión protagonizada por indígenas y mestizos, principalmente, contra los abusos que cometían los curas, hacendados y autoridades. Hacia la segunda década del siglo XIX, los actos de rebeldía se intensificaron, la rebelión de los hermanos Angulo y el accionar de lo morochucos ocasionaron estragos en la economía y debilitaron el poder de las autoridades coloniales, quienes en su afán de derrotar implementaron campañas sangrientas contra aquella población, pero a pesar de ello resistieron hasta el triunfo en la batalla de Ayacucho.

2. La elite de Huamanga constituía españoles, criollos y algunos mestizos exitosos, que ejercieron poder sobre la mayoría de la población gracias a la tenencia de bienes inmuebles, distinción cultural, capacidad económica, ejercicio de cargos en el sector militar, religioso y civil y el sistema colonial que garantizaba los privilegios y status social. También eran conocidos como vecinos notables con estilos de vida y prácticas culturales catalogado "superiores", con la que se diferenciaba del pueblo "incivilizado y salvaje". Fue una elite de composición heterogénea y por consiguiente con intereses diversos hasta divergentes en determinadas ocasiones. y

3. La elite durante el proceso de la independencia actuó de acuerdo a la relación y dependencia que mantenía con el estado colonial, los intereses económicos y políticos y origen social. Los funcionarios y autoridades directamente ligados a la monarquía actuaron en defensa de la corona, no solo por la responsabilidad funcional sino también por defender su condición y privilegios que dependía de ella, constituyeron la facción de realismo absolutista; mientras aquellos miembros que no pertenecían al antiguo círculo de poder, así también los emergentes se mostraron partidarios de la Constitución de Cádiz de 1812, hicieron del ayuntamiento en el principal espacio de aprendizaje del liberalismo y cuando el régimen colonial vislumbraba debilidad, se inclinaron por la independencia en salvaguarda de la misma y alejar a las clases populares de la conducción de la lucha separatista. No faltaron personas con posición ambivalente que actuaban según las posibilidades de obtener beneficios a futuro. 


\section{REFERENCIA BIBLIOGRÁFICA}

Baras, M. (1991) Las élites políticas. Revista del Centro de Estudios Constitucionales, Nº 10, págs. 9-24

Blacha, L. (2005) ¿Élite o clase política? Algunas precisiones terminológicas. Revista Theomai N12. Segundo semestre. Red Internacional de Estudios sobre Sociedad, Naturaleza y Desarrollo.

De la Riva Agüero, J. (1995) Paisajes peruanos. Lima. PUCP.

Eguiguren, L. A. (1935) La sedición de Huamanga en 1812: Ayacucho y la Independencia. Lima, Imprenta Gil.

Fisher, J. (2006) Redes de poder en el virreinato del Peru, 1776-1824: Los burócratas. Revista Indias, vol LXVI, num. 236.pags. 149-164

Foucault, M. (1999). Estrategias de poder. Argentina. Ediciones Paidós Ibérica S.A. Colección Obras Esenciales.

Galdo, V. (1992). Ayacucho, conflictos y pobreza, siglos XVI - XIX. Concytec.

Huertas, L. (1974) Las luchas por la Independencia en Ayacucho. Ponencia I simposio nacional de Historia de la Independencia. Ayacucho.

Hernández, E. (2008) La elite piurana y la independencia del Perú: La lucha por la continuidad en la naciente república (1750-1824). Lima. Instituto Riva AgüeroPontificia Universidad Católica del Perú, Universidad de Piura, 476 p.

Husson, P. (1992) De la guerra a la rebelión (Huanta siglo XIX). Edic. IFEA-CBC.

Igue, J. L. (2008) "Bandolerismo, patriotismo y etnicidad poscolonial: los "morochucos" de Cangallo, Ayacucho en las guerras de independencia, 1814 - 1824” Lima. Tesis de licenciatura en Historia PUCP.

Medina, P. M. (1924) Ayacucho monografía histórica sobre la emancipación del Perú, en homenaje del centenario de la batalla de Ayacucho.

Morán, D. (2010) Reseña de "La elite piurana y la independencia del Perú: La lucha por la continuidad en la naciente república (1750-1824)" de Elizabeth del Socorro Hernández García Bulletin de l’Institut français d'études andines, vol. 39, núm. 1, 2010, pp. 200-203 Institut Français d’Études Andines.

O`Higgins, D. (1826) Informe al ministro de indias don Miguel Cayetano Soler. En Noticias Secretas de América por Jorge Juan y Antonio de Ulloa Landies. Imprenta Taylor.

O’Phelan, S. (2011) La elite nobiliaria y la elite ilustrada frente a la Independencia del Perú. revis. illes i imperis.

Paniagua, V. (2003) Los Orígenes del Gobierno Representativo en el Perú. Las Elecciones $(1809-1826)$.

Pozo, M. (1924) “Lo que hizo Huamanga por la Independencia” Imprenta República 
Quichua, D (2017), Génesis y causas de la Independencia. Huamanga 1786-1800. Summa Humanitatis, vol. 9, número 2 pp. 81-113.

-(2019) La independencia en la región Huamanga y la Universidad de San Cristóbal 1795-1824 UNSCH.

-(2020) Leales y vasallos. Españoles, mestizos e indígenas realistas de Huamanga en la Independencia. Argumentos revista de Ciencias Sociales.

Quiroz, F. (2009) Criollos limeños: entre fidelismo y la separación. En Las independencias desde la perspectiva de los actores sociales. Lima. OEI - UNMSM - PUCP.

Roca, J. (1866) Apuntes póstumos. Relación histórica de la primera campaña del general Arenales a la sierra del Perú, en 1820. Buenos Aires. Imprenta de mayo.

Roel, V. (1988) La Independencia. Historia general del Perú. Lima

Rojas, C. (1995) La élite de Huamanga durante la Independencia 1810 - 1835. Informe de práctica preprofesional. Ayacucho. UNSCH.

------ (2016) La rebelión de 1814 en Huamanga. En 1814: la junta de gobierno del Cuzco y el sur andino. Editora. Scarlett O phelan. Lima. IFEA-PUCP.

Ruiz, J. (1924). Monografía Histórica de Ayacucho. Lima. Imprenta Torres Aguirre.

Sala, N. (1989) Las revueltas indígenas en el Perú tardocolonial. Tesis de doctorado. Universidad de Barcelona.

- (1993) Gobierno colonial, Iglesia y poder en Perú. 1784-1814. Revista Andina, año 11

(2011) El Trienio Liberal en el Virreinato peruano: los ayuntamientos constitucionales de Arequipa, Cusco y Huamanga, 1820-1824. Revista de Indias, vol. LXXI, núm. 253 Págs. 693-728.

(2012) Justicia conciliatoria durante el liberalismo hispano en el Perú: el caso de Huamanga. Anuario de Estudios Americanos, 69, 2, julio-diciembre, 423-450, Sevilla (España).

------ (2016) "Derecho, poder y libertad" a propósito de las batallas por la autonomía jurisdiccional entre las audiencias del Cusco y Charcas (1820-1825) Revista de indias, vol. LXXVI, N. ${ }^{\circ}$ 266. págs. 51-82

Urrutia, J. (1983) De las ferias y circuitos comerciales en Huamanga. En Rev. Allpanchis 21. Cusco. IPA.

Vásquez J. (2011) “Huamanga, Historia Tradición y Cultura”. Ayacucho. Imprenta Publigraf.

-------(2015) Poder y status social de familias huamanguinas: los títulos nobiliarios en la época colonial. Informe de investigación FCS.

Vargas, R. (1971) Historia general del Perú 1776 -1815. Tomo: V. Lima. Carlos Milla Batres editorial 
Zapata, A, Pereyra, N. y Rojas, R (2010) Historia y cultura de Ayacucho. Lima: IEPUNICEF-DED.

\section{CITAR COMO:}

Rojas Porras, N. C., \& Gutiérrez Martínez, J. B. (2021). La élite de Huamanga en la independencia del Perú 1810 - 1824. Puriq, 3(3), 417-434. https://doi.org/10.37073/puriq.3.3.223 